\title{
Changes in the burst lick rate of albino rats as functions of age, sex, and drinking experience
}

\author{
ROBERT N. WELLS and AL L. CONE \\ Lynchburg Training School and Hospital, Lynchburg, Virginia 24505
}

\begin{abstract}
Two studies were conducted to investigate momentary lick rate in the albino rat as a function of age. In Experiment I, 24 albino rats were tested at 25, 35, 55 days of age in a longitudinal design. In Experiment II, two additional groups of 24 subjects each were tested, one only at 35 days and the other only at 55 days, to complete a cross-sectional design at the three ages. Lick rate was found to develop linearly as a function of age except that the cross-sectional males were somewhat slower at 55 days than at 35 days. These findings are consistent with our report that uninterrupted lick rates provide a sensitive measure for dipsogenic treatments and are in direct conflict with earlier reports that infant rats lick at adult rates.
\end{abstract}

In a detailed review of the literature on mammalian lick rate, D. M. Cone (1974) concluded that with the appropriate experimental design and with precise measurement techniques, lick rate in mammals is not an invariant behavior. This conclusion contradicts that of Schaeffer and Huff (1965), who stated that mammals lick at a constant rate independent of age, sex, level of deprivation, and type of fluid consumed.

Cone and Cone (1973) demonstrated that male albino rats lick significantly slower than females; that licking was significantly faster in the nocturnal phase of the circadian cycle; and that circadian amplitude differences were significantly greater for the females than for the males. In addition, they reported significantly faster rates as a function of 6 days experience in the test apparatus even though the subjects were licking a spout identical to that found in the home cage.

Cone, Wells, Goodson, and Cone (1975) have demonstrated that lick rate is functionally related to the traditional dipsogenic variables of hours of deprivation and type of solution. Schaeffer and Premack (1961) allowed 18- and 21-day-old weanling rats access to a $10-\mathrm{mm}$-diam floor-mounted drinking cup. They obtained a measure of lick rate which was within the traditional (Stellar \& Hill, 1952) invariant range of six to seven licks per second, despite considerable individual variability (5.3-11.4 licks/sec). By contrast, Schaeffer and Davis (1973) reported that adult gerbils lick significantly faster than infant gerbils. Both of these studies were cross-sectional.

Significant lick rate differences as a function of dipsogenic treatments result from improved

This research was conducted while the first author was a student at Lynchburg College with the second author as faculty advisor. Reprints may be obtained from Al L. Cone, Lynchburg Training School and Hospital, P. O. Box 1098, Lynchburg, Virginia 24505. experimental design, statistical analyses, and a procedure to quantify lick rate. In the Schaeffer studies, the number of licks per second was counted. In the Cone studies, lick rate was computed as licks per second during bursts. A burst was " 10 or more licks with no interlick interval greater than $1.0 \mathrm{sec}$." Pilot observations have indicated no systematic differences when 1.0- and .5-sec interlick interval criteria are applied simultaneously to the licking of the same subject.

The present research was designed to examine the development of lick rate in the albino rat from weaning to maturity. Both longitudinal and cross-sectional designs were used, and sex and method of home-cage drinking experience was statistically controlled.

\section{EXPERIMENT I: LONGITUDINAL}

Since Cone et al. (1975) report the apparent importance of test apparatus experience, the first experiment was designed to provide graduated experience in the test cage as the subjects matured. This repeat measures design allowed the investigation of experimental factors related to the test environment.

\section{Method}

Subjects. Subjects were 12 male and 12 female Charles River derived albino rats born in Lynchburg College's small animal colony. All were weaned at 24 days of age and housed individually without water until the following day when the study began. Prior to weaning, the water bottle was placed so as to be inaccessible to the pups. The colony room was maintained at a temperature of $21-23^{\circ} \mathrm{C}$ and humidity $38 \%$. Throughout the experiment, an LD 12:12 (on $0600 \mathrm{~h} /$ off $1800 \mathrm{~h} \mathrm{DST}$ ) lighting cycle was maintained.

Apparatus. The apparatus used in both of the following studies was identical to that used by Cone and Cone (1973).

Procedure. Subjects were tested at 25,35 , and 55 days of age. All were water deprived on Days 24 and 25. Half of the subjects had free access to a water bottle in the home cage from Day 26 until $24 \mathrm{~h}$ before each test; the other half had free access 
to a water cup ( $41 \mathrm{~mm}$ in diam) mounted in the home cage until $24 \mathrm{~h}$ before each test. Thus, all subjects were run on $24 \mathrm{~h}$ deprivation. Standard acclimation day procedures (Cone \& Cone, 1973) were run until a minimum of $10 \mathrm{~min}$ of data with a total of at least five bursts of 10 or more licks was recorded. The criterion of no interlick interval greater than $1 \mathrm{sec}$ was used.

\section{Results}

Lick rates were computed for each burst within each test session by dividing licks in the burst by burst duration measured to .1 sec. Unweighted session means were then calculated and treated as a 2 (sex) by 2 (home cage method of intake) by 3 (age) ANOVA with repeat measures on the last factor. Lick rate increased significantly as a function of age $(\mathrm{F}=87.17,2 / 60, \mathrm{p}<.0001)$ with means of 5.41 , 6.45 , and 6.88 , respectively.

There was no systematic difference between male and female lick rates when examined across all three age groups. Home cage method of intake produced a significant effect, with subjects given access to a cup in the home cage drinking faster in the test environment than subjects raised with a water bottle $(F=6.91,1 / 60 ; p<.01)$. Across age groups, the means were $5.12,6.33$, and 6.88 for the bottle-raised

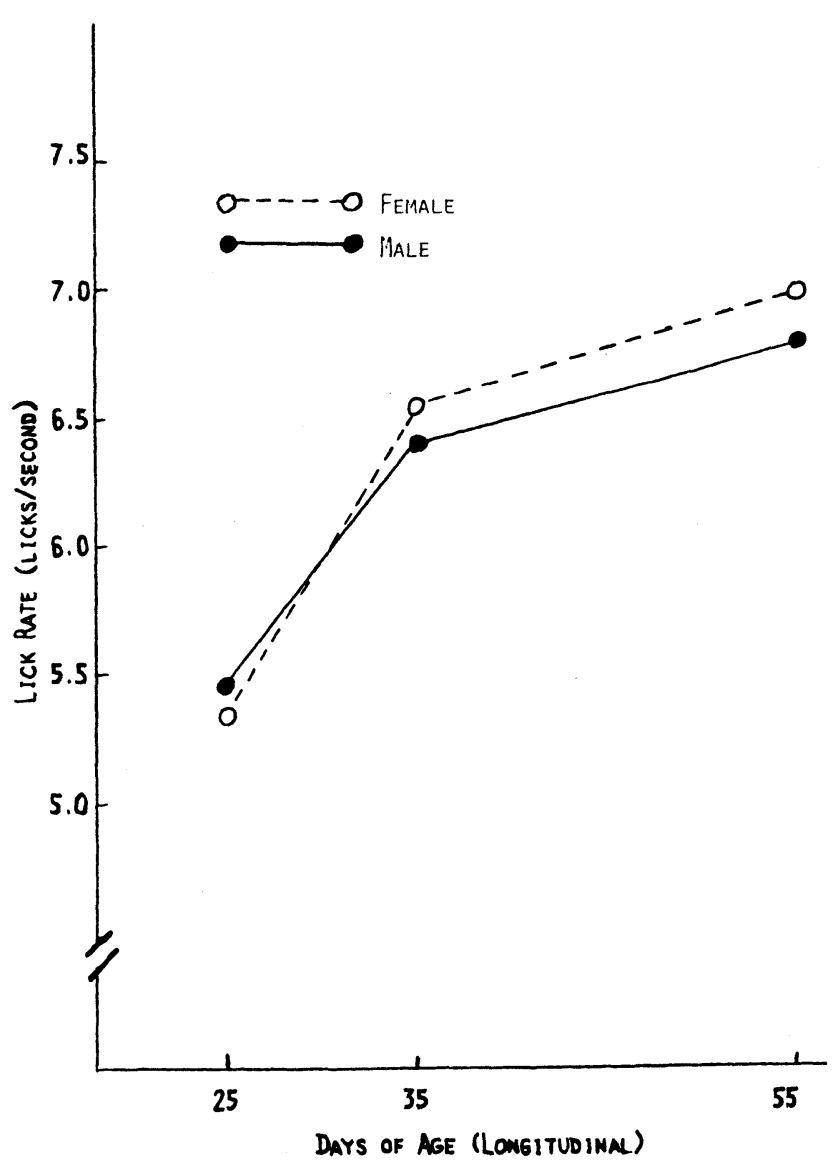

Figure 1. Mean momentary lick rate as a function of longitudinal age in Experiment $\mathbf{I}$. subjects and 5.70,6.58, and 6.90 for those raised with a cup in the home cage. Sex and age showed no significant interaction (Figure 1).

\section{EXPERIMENT II: CROSS-SECTIONAL}

In view of the findings of Cone et al. (1975), it appeared appropriate to also restrict the amount of test apparatus experience. Experiment II was designed to examine two additional age groups (35 and 55 days) with no prior experience in the test apparatus and to compare their scores with the scores of the 25-day-old naive subjects in Experiment I.

\section{Method}

Subjects. New subjects were 24 male and 24 female Charles River derived albino rats born at Lynchburg College's small animal colony at the same time as the subjects in Experiment $I$. All were weaned at 24 days of age and housed individually without water until the following day when the two different methods of home cage intake used in Experiment I were introduced. All other conditions in the colony room were identical to those described in Experiment I.

Apparatus. The apparatus was identical to the one used in Experiment $I$.

Procedure. Twelve males and 12 females were randomly assigned to be tested at 35 days of age. The remaining subjects were then assigned to the 55-day-old testing group. In order to establish continuity between the two experiments and to provide a greater chance for meaningful comparisons, the 25-days-of-age data from Experiment I was treated as the initial age group. This maneuver was possible since the subjects reported in the first experiment were naive with respect to the apparatus on Day 25. Within both the 35-day-old and 55-day-old groups, half of the subjects received free access to a water bottle in the home cage from Day 25 until $24 \mathrm{~h}$ before their respective test days. The other half had free access to a water cup $(41 \mathrm{~mm}$ in diam) in the home cage. Acclimation day and data collection procedures were identical to those described in the previous study.

\section{Results}

Lick rates were computed and treated through procedures identical to those reported in Experiment I. Data were treated as a 2 by 2 by 3 complete factorial randomized group design. The difference between male and female lick rates, looked at cross-sectionally for all three age groups, approached customary levels of significance $(\mathrm{F}=3.36,1 / 60 ; \mathrm{p}<.07)$; however, sex and age interacted significantly $(\mathrm{F}=7.54, \quad 2 / 60$; $\mathrm{p}<.002$ )(Figure 2). Mean burst rates for the males were $5.44,6.62$, and 6.00 across the three age levels; means for the females were $5.38,6.40$, and 7.15 , respectively. Lick rate was again shown to be significantly related to age $(F=22.77,2 / 60$; $\mathrm{p}<.0001)$. Variability associated with method of home cage water consumption did not approach significance.

\section{Discussion}

Schaeffer and Davis (1973) found that lick rate in the gerbil increased as a function of age, a finding which Pierson and 


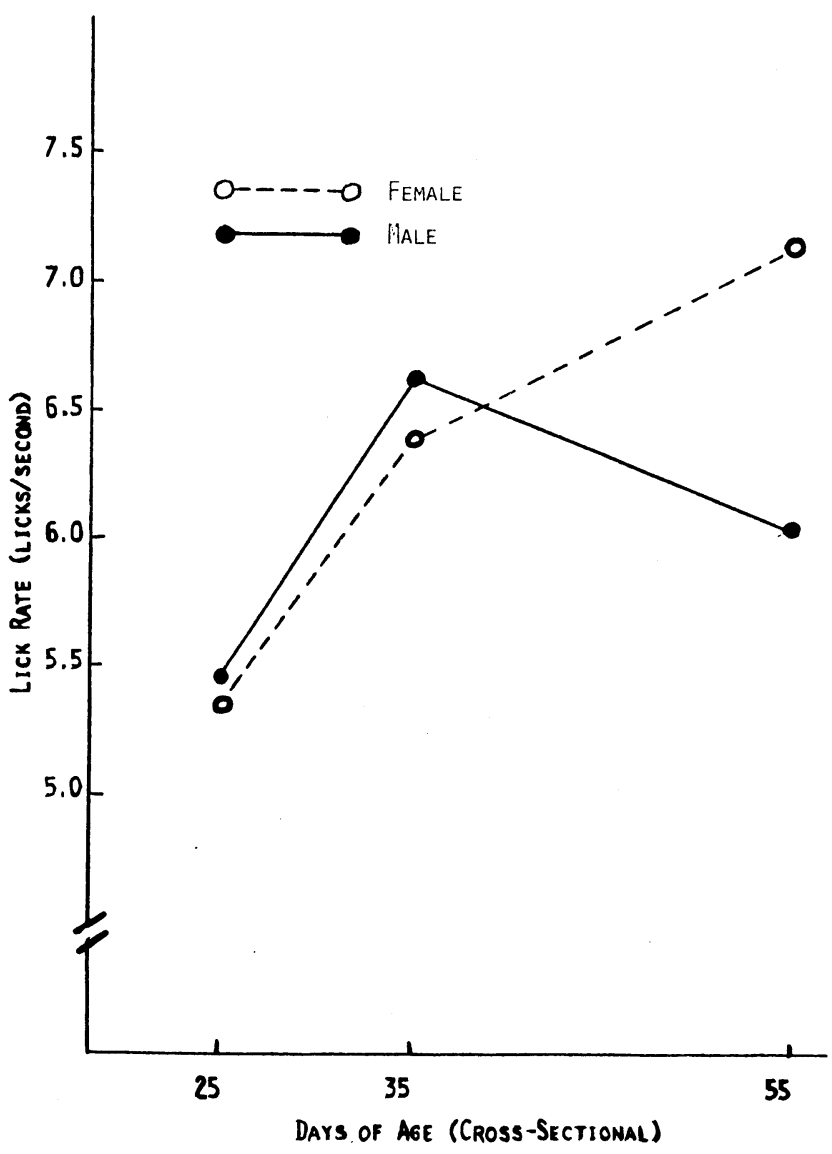

Figure 2. Mean momentary lick rate as a function of crosssectional age in Experiment II.

Schaeffer (1975) were unable to replicate. The present studies demonstrate an increased lick rate as a function of age for the rat and, therefore, are in conflict with the findings of Schaeffer and Premack (1961). Indeed, the data presented here may be taken to support a general, but rather complex, developmental lick rate trend in the albino rat.

This complexity results from several variables, the most conspicuous of which is an interaction between age and experience in the test apparatus which may be seen by comparing Figures 1 and 2. The original hypothesis of a monotonic increase in lick rate as the subjects matured, though observed, did not manifest itself in simple terms. Regardless of home-cage method of intake, those subjects tested at all three age levels-thereby receiving more test apparatus experience than the cross-sectional 35-day-old males-appear to be in a transient, accelerated state exhibiting over .5 licks/sec more than at maturity.

The finding that males with test-apparatus experience continue to accelerate their licking rates through the 55th day is the only result not consistent with our previous findings. Cone and Cone (1973) found that 6 consecutive days of experience in the test apparatus was not sufficient to reduce the rate differential associated with sex of adult rats and suggested that lick rate and tongue size may be inversely related as previously reported by Davenport (1961). It would appear that early and regular exposure to the test apparatus is sufficient to obviate this possible biological constraint on lick rate in male rats.

Since the bottle/cup variable was not introduced until Day 25 or 26 , meaningful comparisons across all ages cannot be made for this variable. In fact, an ex post facto analysis at age 25 days indicated that subjects which were to be randomly assigned to the cup condition had licked faster $(F=8.20 ; 1 / 22 ; \mathrm{p}<.01)$ than subjects which were to be randomly assigned to the bottle condition. Though adequate randomization procedures were employed, we built in a significant difference between treatments which was never overcome.

Friedman and Campbell (1974), in investigating three different physiological stimuli for thirst, noted that each of the three (intracellular dehydration, intravascular dehydration, and angiotensin) had different effects on elicitation of drinking behavior at different ages. Differential maturation well may be at work. The present findings, though dealing solely with $24-\mathrm{h}$ deprivation dehydration, clearly are in agreement with such an interpretation. Namely, the effects of deprivation on lick rate differs as a function of age. To this we would add that these differential effects of age are neither independent of sex, nor amount of test cage experience.

The data presented in this paper support our recent research indicating that a variety of dipsogenic treatments produce small, but certainly quite reliable, changes in burst lick rates. These data, along with those of Schaeffer and Davis (1973) for gerbils lead to the inescapable conclusion that burst lick rate is not an inborn, genetically determined behavior as Schaeffer and Premack (1961) originally hypothesized. Clearly, both maturational and experiential variables are involved in the ultimate expression of adult licking patterns. Factors related to experience in the test apparatus remain more crucial than experience in the home cage.

\section{REFERENCES}

Cone, A. L., \& Cone, D. M. Variability in the burst lick rates of albino rats as a function of sex. time of day, and exposure to the test situation. Bulletin of the Psychonomic Society, 1973, 2, 283-284.

Cone, A. L., Wells, R. N., Goodson, L., \& Cone, D. M. Changing the burst lick rate of rats by manipulating deprivation and type of solution. The Psychological Record', 1975. Fall.

Cone, D. M. Do mammals lick at a constant rate? A critical review of the literature. The Psychological Record, 1974. 24. 353-364.

DAVENPORT, R. K. An investigation of the drinking behavior of the white rat. Doctoral dissertation, University of Kentucky, Änn Arbor, Michigan: University Microfilms No. 61-294, 1961.

Friedman, M. I., \& Campbell, B. A. Effects of hypertonic saline, polyethylene glycol, and vena cava ligation. Journal of Comparative and Physiological Psychology, 1974, 87. $37-46$.

Pierson, S. C., \& Schaeffer, R. W. Lick rate development in infant Mongolian gerbils. Bulletin of the Psychonomic Society. 1975, 5, 47-48.

SChAEFFER, R. W., \& Davis, M. Lick rates in gerbils. Bulletin of the Psychonomic Society. 1973, 2, 257-260.

Schaeffer, R. W., \& HufF, R. Lick rates in cats. Psychonomic Science, 1965, 3, 377-378.

Schaeffer, R. W.. \& Premack, D. Licking rates in infant albino rats. Science, 1961, 134. 1980-1981.

Stellar, E., \& Hill, J. H. The rat's rate of drinking as a function of water deprivation. Journal of Comparative and Physiological Psychology. 1952. 45. 96-102.

(Received for publication September 15, 1975.) 